\title{
Maximum Voxel
}

National Cancer Institute

\section{Source}

National Cancer Institute. Maximum Voxel. NCI Thesaurus. Code C94932.

The largest activity concentration occurring for a voxel within a volume of interest. 